\title{
Electrochemical Characterization of Nickel in Oxalic Acid Solutions and the Effect of Halides and Azide Ions Additions on Its Behavior
}

\author{
F. El-Taib Heakal ${ }^{1, *}$, O.S. Shehata ${ }^{2}$, N.S. Tantawy ${ }^{3}$ \\ ${ }^{1}$ Chemistry Department, Faculty of Science, Cairo University, Giza 12613, Egypt. \\ ${ }^{2}$ Physical Chemistry Department, National Research Centre, Dokki, Giza 12622, Egypt. \\ ${ }^{3}$ Faculty of Women for Arts, Science and Education, Ain Shams University, Cairo, Egypt. \\ *E-mail: fakihaheakal@yahoo.com, feltaibheakal@gmail.com
}

doi: $10.20964 / 2017.10 .31$

Received: 9 May 2017 / Accepted: 19 July 2017 / Published: 12 September 2017

\begin{abstract}
The electrochemical behavior of polycrystalline nickel in aqueous oxalic acid solutions was thoroughly investigated using different electrochemical techniques. Open circuit potential (OCP) transients of $\mathrm{Ni}$ electrode indicate different natural tendencies for the metal to modify its pre-immersion native film in oxalic acid medium depending on its concentration and temperature. In agreement with the OCP results, electrochemical impedance spectroscopy (EIS) clearly demonstrates that surface film resistance $\left(R_{\mathrm{f}}\right)$ on $\mathrm{Ni}$ increases with concentration over the range 0.01-0.5 M, but decreases with raising temperature. Also, linear sweep voltammetry (LSV) was used to compare at similar experimental conditions hydrogen evolution reaction (HER) on nickel cathode to that on platinum which has high catalytic activity towards HER. Furthermore, addition of different sodium halides or azide to $0.5 \mathrm{M}$ oxalic acid solution (blank) was found to increase the propensity of nickel to dissolution in the following order: $\mathrm{I}^{-}<\mathrm{F}^{-}<$blank acid $<\mathrm{Cl}^{-}<\mathrm{Br}^{-}<\mathrm{N}_{3}^{-}$(the most aggressive). These findings are discussed based on the kosmotrope/chaotrope nature of the added anions and further validated by SEM examination.
\end{abstract}

Keywords: Nickel metal; Oxalic acid; Halides; Azide ions; EIS; LSV; SEM; Film resistance.

\section{$\underline{\text { FULL TEXT }}$}

(C) 2017 The Authors. Published by ESG (www.electrochemsci.org). This article is an open access article distributed under the terms and conditions of the Creative Commons Attribution license (http://creativecommons.org/licenses/by/4.0/). 